\title{
THE ECONOMIC CONSEQUENCES OF \\ PARENTAL LEAVE MANDATES: \\ LESSONS FROM EUROPE
}

Christopher J. Ruhm

NBER Working Paper 5688

\section{NATIONAL BUREAU OF ECONOMIC RESEARCH 1050 Massachusetts Avenue \\ Cambridge, MA 02138 \\ July 1996}

I would like to thank David Blau, Andrew Brod, Bruce Meyer, Ken Snowden and workshop participants at the Center for European Economic Research, Northwestern University, Princeton University, University of North Carolina at Chapel Hill, University of North Carolina Greensboro, University of Wisconsin, and the Society of Labor Economists meetings for helpful comments on earlier versions of this manuscript. This paper is part of NBER's research programs in Health Care, Labor Studies and Public Economics. Any opinions expressed are those of the author and not those of the National Bureau of Economic Research.

(C) 1996 by Christopher J. Ruhm. All rights reserved. Short sections of text, not to exceed two paragraphs, may be quoted without explicit permission provided that full credit, including $($ notice, is given to the source. 


\title{
THE ECONOMIC CONSEQUENCES OF \\ PARENTAL LEAVE MANDATES: \\ LESSONS FROM EUROPE
}

\begin{abstract}
This study investigates the economic consequences of parental leave mandates using data for 16 European countries over the 1969 through 1988 period. Since women use virtually all of the family leave in most nations, men constitute a reasonable comparison group and the natural experiment in most of the analysis involves examining how changes in leave entitlements affect the gap between female and male labor market outcomes. The employment-to-populations ratios of women in their prime childbearing years are also compared to those of older females, as a function of changes in leave regulations. Parental leave mandates are associated with increases in total employment but appear to have a more modest effect on weekly work hours and there is some evidence that women pay for entitlements to extended leave by receiving lower relative wages. The econometric estimates are sensitive to the inclusion of controls for time-varying country effects and sex-specific within-country time-trends.
\end{abstract}

Christopher J. Ruhm Department of Economics University of North Carolina Greensboro Greensboro, NC 27412-5001 and NBER 


\section{The Economic Consequences of Parental Leave Mandates: Lessons From Europe}

Despite widespread international implementation, little is known about the economic effects of government policies requiring companies to allow their employees to take time off work during the period surrounding the birth of a child. ${ }^{1}$ Proponents believe that parental leave results in healthier children and improves the position of women in the workplace. Opponents counter that the mandates, by restricting voluntary exchange between workers and employers, reduce economic efficiency and may have a particularly adverse effect on women.

This study investigates the labor market consequences of parental leave policies using data for 16 European countries over the 1969 through 1988 period. ${ }^{2}$ The dependent variables include employment-to-population (EP) ratios, weekly work hours (HOURS), and hourly wages (WAGES). Since women use virtually all of the family leave in most countries, men are likely to provide a reasonable comparison group and the "natural" experiment involves examining how changes in leave entitlements affect the gap between female and male outcomes. Limited analysis is also undertaken contrasting the EP ratios of 25-34 year old women to those of their counterparts aged 45-54. The younger cohort are in their prime childbearing years and so should be strongly affected by leave mandates. Conversely, virtually all of the older women have completed their fertility and so they may provide a useful comparison group. In both cases, time and country effects are also controlled for to provide "difference-in-difference-in-difference" (DDD) estimates.

1 By 1991, over 100 countries had passed some form of parental leave policies, with most assuring at least two to three months of paid job absences (Kamerman, 1991).

2 A distinction is sometimes made between "maternity leave", which is granted to mothers for a limited period around the time of childbirth, and "parental leave" which permits additional time off work to care for infants or young children. Both types of entitlements are included in the definition of parental leave (also referred to as family leave) used below. 
To preview the results, parental leave entitlements are associated with increases in the female employment-to-population ratio, while having a weaker and less certain impact on weekly work hours. Conversely, there is some evidence that women pay for rights to extended time off work by receiving lower relative wages. These results are somewhat sensitive to the choice of specifications and, in particular, it is important to include controls for country-specific time effects and sex-specific time-varying country effects.

European data are particularly useful for investigating the effects of parental leave. All Western European countries currently offer at least 3 months of paid maternity benefits; however, many of the policies have been instituted or revised during the last 25 years, resulting in substantial variation, over time and across countries, in the type and duration of the entitlements. Conversely, the United States did not require employers to offer family leave until the 1993 passage of the Family and Medical Leave Act (FMLA) ${ }^{3}$

Obtaining a better understanding the effects of parental leave mandates is important in both the European and U.S. contexts. Europe has been grappling with the question of whether extensive social protections inhibit economic flexibility and are a cause of low rates of recent employment growth. ${ }^{4}$ These concerns have led a number of countries (e.g. Finland, Denmark, and Sweden) to reduce payments provided during the leave period, at the same time that other nations (e.g. Austria, Germany, and Norway) have increased them (Organization for Economic

3 The FMLA mandates companies with more than 50 workers to allow 12 weeks of leave following the birth or adoption of a child or to care for seriously ill relatives. Health insurance contributions must be continued during the period but the leave is unpaid. Firms may exempt the highest paid $10 \%$ of their workforce and persons employed less than 1250 hours during the previous year. Klerman \& Leibowitz (1995) estimate that these restrictions limit coverage of the law to $31 \%$ of working women. Ten states (and the District of Columbia) legislated job-protected work absences prior to the FMLA and 8 others provided limited rights to parental leave, without guaranteeing the reinstatement of employment (Waldfogel, 1994). Most of the state laws were enacted in the late 1980 s or early 1990 s and included numerous exemptions. 4 Blank (1994) summarizes a series of investigations of the effects of social welfare policies in Europe and the United States. The general conclusion is that differences in the policies are unlikely to explain much of the disparity between U.S. and European experiences. 
Cooperation and Development, 1995). Conversely, advocates (e.g. the Carnegie Task Force on Meeting the Needs of Younger Children, 1994) have argued for broadening the U.S. law to include small employers and provide payment during the time off work.

\section{The Economics of Parental Leave Mandates}

In a competitive spot labor market with perfect information and no externalities,

mandated benefits such as parental leave reduce economic efficiency by limiting the ability of employers and workers to voluntarily select the optimal compensation package. Instead, firms are required to provide the entitlements even when the costs exceed the benefits of doing so. Since these expenses will be passed on to workers, the decrease in effective compensation results in a deadweight efficiency loss. If firms are constrained in their ability to reduce pay (e.g. by minimum wages), the employment reductions and efficiency losses may be larger still. ${ }^{5}$

Supporters of leave entitlements often argue that they will improve the health and well-being of children (e.g. see Zigler, Frank, \& Emmel, 1988; Carnegie Task Force on Meeting the Needs of Younger Children, 1994). This might occur if the benefits represent externalities which are not adequately valued by agents negotiating labor contracts. For example, the gains might not be fully taken into account if workers have inadequate information concerning the advantages of staying at home with infants or if they pay only a portion of the costs of their children's medical care (as with most types of health insurance). Undervaluing might also occur if parents have higher than socially optimal discount rates, since some of the benefits occur far in the future, or if the welfare of children receives a relatively low weight in their utility function. ${ }^{6}$ Employers may also be less aware or supportive of the advantages of family leave to dependents than of corresponding benefits to the workers themselves. Previous research

5 See Summers (1989), Mitchell (1990), or Krueger (1994) for detailed discussions of the effects of mandated benefits.

6 Conversely, parents could overvalue the benefits to children, leading to excessive parental leave. 
provides little indication of whether this type of externality actually leads to serious underprovision of voluntarily supplied leave.

Proponents also frequently assert that parental leave mandates place women on a more equal footing with men in the workplace (e.g. see Kamerman, 1988; Bookman, 1991; Bravo, 1991; Trycinski, 1991). Without such entitlements, they argue that females experience high rates of unemployment and losses of firm-specific human capital because they must frequently change jobs if they wish to spend time at home with infants and young children. Lacking some source of market failure, this equity argument is unconvincing. First, employers and workers can always voluntarily negotiate maternity leave, thus mitigating the joblessness and retaining the specific investments. Second, with competitive labor markets, the groups most likely to use parental leave will pay for it by receiving lower wages. Hence, females of childbearing age will continue to obtain lower (and possibly reduced) compensation if the benefit is mandated. ${ }^{7}$ Third, entitlements which allow substantial time off work may lead employers to limit women to jobs where absences are relatively less costly, thereby increasing occupational discrimination. ${ }^{\mathrm{B}}$

Adverse selection under asymmetric information provides a potential source of market imperfection. Individuals have better information than firms concerning the likelihood of using parental leave. A company voluntarily offering leave will therefore attract a disproportionate number of "high-risk" employees and be forced to pay lower wages. Persons with small probabilities of using the benefit avoid these firms and so will do without even socially optimal leave. ${ }^{9}$ A government mandate eliminates the incentive for this type of sorting behavior and has the potential to raise welfare. ${ }^{10}$

7 See Gruber (1994) for an excellent discussion of the effects of group-specific mandates. * Stoiber (1990) claims that the exceptional degree of sex discrimination of the Swedish labor force is partially the result of the extensive family leave entitlements in that country.

9 This is analogous to Rothschild \& Stiglitz's (1976) argument for market failure in insurance markets. Aghion \& Hermalin (1990) raise the possibility that socially optimal parental leave will not be voluntarily provided to any workers. In their model, low-risk individuals signal this to 
U.S. data for the pre-FMLA period indicates that companies voluntarily provided explicit paid leave relatively infrequently. Although maternity leave was available to $37 \%$ of full-time employees in medium and large establishments (greater than 100 workers) in 1991 and $18 \%$ of those working for small employers in 1992 , just $2 \%$ and $1 \%$, respectively, of the job-holders were entitled to time off work with pay (U.S. Department of Labor, Bureau of Labor Statistics, 1993, 1994). These low coverage rates suggest that market imperfections may limit the unregulated provision of parental leave and particularly of paid work absences. ${ }^{11}$ Alternatively, most workers may believe that the costs of the entitlements exceed the benefits.

Although parental leave statutes might be expected to increase the time away from work by mothers of young children, Klerman \& Leibowitz (1995) demonstrate that the effect is actually ambiguous. The intuition of their argument can be summarized as follows. Let $L_{a}$ represent the amount of leave which will be taken in the absence of a mandate (where $L_{a}$ is a function of leave benefits, reemployment wages etc.). Next impose a leave guarantee of $L_{m}$. If $L_{m}>L_{a}$, the entitlement will either have no effect on or will increase the duration of the work absence. In particular, the latter may occur if the statute sufficiently reduces the costs to the worker of additional time off the job. Conversely, consider the case where $L_{m}<L_{a}$. The

employers by agreeing to contracts with no (or limited) leave provisions. High-risk workers sometimes do better by mimicking their counterparts (by taking positions without leave) than by revealing their propensity towards absenteeism. Another reason why socially optimal leave might not be provided is that large firms may set compensation policies according to the preferences of the median worker, who may obtain little benefit from rights to parental leave. 10 The potential inefficiency of privately negotiated labor contracts under asymmetric information has been demonstrated across a variety of contexts. For example, McGuire \& Ruhm (1993) indicate that employer-drug testing is likely to be excessive, whereas Levine (1991) and Kuhn (1992) show that just-cause employment security regulations and advance notice of job terminations will generally be underprovided.

1 Some women are able to take short-periods of time off work even when formal leave policies do not exist (i.e. through the use of accumulated sick leave and vacation or temporary disability policies). Klerman \& Leibowitz (1994) estimate that, between 1979 and $1982,5 \%$ of women with one month old children were on paid leave and $10 \%$ were using unpaid leave. By the time the children were 4 months old, the percentages had fallen to $1 \%$ and $2 \%$ respectively. 
worker must now decide between taking $\mathrm{L}_{a}$ or $\mathrm{L}_{m}$ weeks of leave. The decision will be to choose $L_{m}$ if $U\left(L_{m}\right)>U\left(L_{a}\right)$, where $U($.$) shows the utility associated with the specified amount of leave.$ This condition will be fulfilled if the gains from returning to the old employer (e.g. higher wages, increased job security) exceed the costs of reducing the leave period by the amount $L_{a}-L_{m}$. The key point to note is that by permitting return to the old job after a work absence of $L_{m}$ the marginal cost of additional time off work (beyond $L_{m}$ ) increases and it may become worthwhile to reduce the duration of leave. If this effect dominates, the mandate will raise, rather than lower, the employment of women with infants. ${ }^{12}$

Next consider the effects of parental leave statutes on all women, rather than just those with young children. Some previous researchers (e.g. Gruber \& Krueger, 1991; Gruber, 1994; Anderson \& Meyer, 1995) have evaluated the efficiency consequences of similar group-specific mandates by examining whether firms pass the associated costs through to employees by reducing wages. To illustrate, consider Figure 1, which shows the market demand and supply curves for the specified group (e.g. women). The mandated benefit shifts the supply curve to the right and the demand curve to the left, since total compensation rises at given wage levels. Complete pass-through occurs if workers value compensation equally in the form of wages or benefits. This corresponds to a change in the labor market equilibrium from point $B$ to $E$, whereby employment and total surplus are unchanged (with the latter shown by the identical triangles $A B C$ and $D E F)$ and wages fall by the cost of the benefit (C). Conversely, if workers place a lower (higher) value of compensation in the form of the mandated benefit rather than wages, the supply curve shifts to the right by less (more) than $S_{2}$, implying that wages fall by a smaller (larger) amount than the increase in benefit costs and that total surplus declines (rises).

12 Some individuals may also increase their labor supply prior to having children, in order to meet the qualification conditions for parental leave. Mortensen (1977) makes an analogous point with regard to unemployment insurance. 
Although cost-shifting provides a reasonable metric for evaluating static efficiency effects when firms pay for the mandated benefit (either directly or through payroll taxes), changes in employment may be more informative when dynamic considerations are introduced or if the benefits are financed out of general government revenues. For example, it is frequently asserted that parental leave raises levels of firm-specific human capital, by allowing women to return to their old jobs after having children. This elevates the marginal revenue product of workers, causing a rightward shift in the demand curve. For simplicity, assume that the increase in human capital returns the demand curve to $D_{1}$, with the new equilibrium occurring at point $\mathrm{G}$. Whereas efficiency was unchanged in the static analysis, the long-run effect of the entitlement is to boost the sum of producer and worker surplus to AGF. Notice that the final wage reduction $\left(W_{1}-W_{3}\right)$ is less than the cost of the parental leave benefit, erroneously suggesting an efficiency loss when using the pass-through criteria. Conversely, employment is raised by mandates which increase either static or dynamic efficiency. ${ }^{13}$

Alternatively, assume that benefits are paid out of general tax revenues, as with parental leave in many European countries. If firms do not bear any costs of the entitlements, the (static) demand curve remains unchanged at $D_{1} \cdot{ }^{14}$ If the financing is by nondistortionary taxes, the supply curve will again shift to $S_{2}$ and total surplus will increase from ABC to AGF. Efficiency and employment continue to be positively related while wages fall by less than the cost of the benefit, with the result that the pass-through criteria once again erroneously suggests a decline in total surplus. The more realistic case of financing by distortionary taxes

13 A mandate which reduces productivity (e.g. because the lengthy period away from work results in the depreciation of human capital) will cause the demand curve to shift to the left of $D_{2}$. This decreases both employment and total surplus, and leads to an additional fall in wages. ${ }_{14}$ More frequently, firms will continue to incur some costs, even when payments to workers are provided by the government (e.g. expenses associated with hiring and training temporary replacements). In this case, the demand curve will shift to the left of $D_{1}$, although by a lesser amount than if benefits were paid directly by employers. 
would be represented by additional movements of the supply or demand curves. For instance, higher personal (corporate) income taxes are likely to shift the supply (demand) curve to the left, reducing employment compared to the case of nondistortionary taxation. If these shifts are sufficiently large, total surplus and employment may fall. Thus, across a wide variety of situations, parental leave mandates which increase (decrease) economic efficiency will result in higher (lower) levels of employment, while having less predictable effects on wages. ${ }^{15}$

\section{Previous Research}

Early studies by Dalto (1989) and Spalter-Roth \& Hartmann (1990) indicate that women are out of work for less time and receive higher wages, following the birth of a child, if their employers voluntarily provide maternity leave than if they do not. However, it is not clear whether these advantages are actually caused by the entitlements or if they result from nonrandom selection into jobs providing the benefit.

Waldfogel $(1994,1995)$ partially circumvents this problem by estimating first-difference and fixed-effect models (which control for time-invariant individual characteristics) using U.S. and British data from the National Longitudinal Surveys and the National Child Development Study respectively. Mothers returning to the same firm within twelve months of childbirth are shown to experience substantially faster wage growth than those switching companies, with preservation of job tenure playing an important role in explaining the superior performance. However, data limitations require Waldfogel to restrict most analysis to the effects of rejoining the same employer, rather than focusing directly on parental leave. Thus, women taking no time or just a few days off work are grouped with those using extensive maternity leave.

15 There may also be distributional consequences. For instance, a leave benefit which is financed by personal income taxes may raise the welfare of women while reducing that of men. In such cases, it is difficult to determine whether efficiency rises or falls. 
Furthermore, the differencing techniques do not completely eliminate biases caused by nonrandom selection into employment. ${ }^{16}$

Three studies provide evidence on legislated parental leave entitlements. Klerman \& Leibowitz (1995) examine the effects of state maternity leave mandates, using 1980 and 1990 census data for the United States. ${ }^{17}$ Their findings, although somewhat ambiguous, indicate that rights to time off work have employment effects which range from slightly negative to substantially positive. ${ }^{18}$ Waldfogel (1996) investigates the impact of the Family and Medical Leave Act utilizing data from the 1992-1995 March Current Population Surveys. She uncovers little evidence of a wage effect but concludes that the FMLA has modestly increased employment. This last finding is sensitive to the model estimated, however, with some specifications indicating a negative or inconsistent impact of the law. ${ }^{19}$ Finally, Ruhm \& Teague (1995) study the impact of changes in federal leave legislation using data for 17 nations over the 1968-1988 period. After controlling for country and year effects, they find that short to moderate durations of parental leave (through at least one year) are positively related to per capita incomes and labor market outcomes, whereas lengthier entitlements have less beneficial effects or negative impacts. However, they do not clearly identify the direction of causation (i.e.

16 In particular, Waldfogel (1995) finds that mothers with the option of taking maternity leave but not doing so experience faster wage growth than corresponding mothers without coverage. This suggests that women with relatively steep wage profiles disproportionately work in positions offering the leave.

17 No states had adopted mandates by 1980, whereas six (Minnesota, Rhode Island, Oregon, Wisconsin, Maine, and Washington) had done so by 1990.

${ }_{18}$ The ambiguity occurs because mothers of somewhat older children, who should be less affected by maternity leave provisions, experience higher rates of employment growth when states institute parental leave entitlements than do women with infants.

19 For example, the employment of women with children under one year of age increased faster, after passage of the FMLA, in states that already had a maternity leave mandate in place than in those that did not, even though the federal legislation would be expected to have a stronger impact in the latter states. 
countries might extend durations when the economy improves), possibly leading to an overestimate of the benefits of leave. ${ }^{20}$

\section{Parental Leave Policies in Europe}

Legislated maternity benefits have a long history in Europe. The German Imperial Industrial Code of 1891 set maximum work hours and prohibited the employment of women within four weeks of childbirth. Amendments to the code in 1903 and 1911 increased the leave period to six weeks and supplied women with paid time off work in the two weeks before delivery. By turn of the century there was discussion of providing maternity insurance in many European countries. ${ }^{21}$ Most early legislation was paternalistic in its concern for the health of the child and mother. Prenatal and postnatal leave was typically compulsory and supplementary income support or job-protection seldom provided. For example, the 1919 and 1952 International Labor Organization Maternity Protection Conventions recommended that women not be permitted to work during the six week period following confinement. ${ }^{22}$

The pronatalist rationale became explicit in social policies across Europe after the end of World War II. Many nations which had recruited women into previously male-dominated occupations wished to return them to the home (Moeller, 1993). The motivation for policies related to family allowances, protective legislation, and family-law reform was often to restore women to their "proper" roles as mother and wife (Frank and Lipner, 1988). During the

20 Furthermore, Ruhm \& Teague uncover litile evidence that the entitlements have stronger impacts on females alone than for men and women together. Since females are the main users of family leave, and so should receive the majority of any benefits, this suggests that concerns about dual causation may be warranted.

21 See Frank \& Lipner (1988) for a detailed discussion of early maternity leave policies.

22 The 1919 convention advocated a 12 week period away from work, payment during the duration of the leave, and job-reinstatement upon return to employment. The 1952 conference recommended a cash benefit equal to at least two-thirds of previous earnings, compared a previously suggested unspecified amount "sufficient for the full and healthy maintenance of the working mother and her child" (International Labor Office, 1984). 
post-war period some countries (e.g., Denmark, Finland, Greece, the Netherlands, and France) mandated compulsory pregnancy leave but failed to prohibit dismissal from jobs.

By the late 1960s, the concept of maternity leave began to evolve from a prohibition on employing women during the period surrounding childbirth to one of job-protected time off work to care for newborns and young children. Portugal, Spain, and Finland instituted employment reinstatement provisions during the 1969-1971 period; France and the Netherlands passed similar legislation in 1975 and 1976; as did Denmark, Ireland and Greece between 1980 and 1984. Other nations (e.g. Switzerland and the United Kingdom) inaugurated regulations which provided for job-protected maternity leave during this time span. Nonetheless, vestiges of protective legislation persist in some countries. Postnatal leaves remain compulsory, rather than voluntary, in Austria, Finland, France, Germany, Norway, Spain, Sweden, and Switzerland; Austria, France, and Italy continue to require prenatal leave (Brocus, et. al., 1990).

Income support is provided during at least a portion of the work absence throughout Western Europe. Wage replacement rates often exceed $80 \%$ and payments are usually supplied through social insurance, although some nations (e.g. Belgium, Germany, Italy, and the United Kingdom) require an employer contribution. A few countries have recently reduced benefit replacement rates, however, the overall trend has been towards longer paid and total leave periods, with fathers increasingly gaining rights to time off work (Organization of Economic Cooperation and Development, 1995). The European Community Social Charter recently established a minimum standard leave period of 14 weeks, with pay no less than the individual would receive if absent from work because of sickness (Addison \& Siebert, 1993).

Even where parental leave extends to fathers, mothers take the vast majority of actual time off work. For instance, males accounted for $7 \%$ of total absences in Sweden in 1988 but a dramatically smaller proportion of weeks in other European countries (Organization of 
Economic Cooperation and Development, 1995). ${ }^{23}$ There are a variety of reasons why men use the leave so sparingly. In addition to cultural norms and differences in earnings capacity, the entitlements are generally restricted to mothers during the period immediately surrounding confinement and fathers can frequently subsequently take time off work only if the mother qualifies for but waives her rights to it.

\section{Data}

This analysis uses aggregate data for 16 European countries (Austria, Belgium, Denmark, Finland, France, Germany, Greece, Ireland, Italy, the Netherlands, Norway, Portugal, Spain, Sweden, Switzerland, and the United Kingdom) over the 1969 through 1988 period. The information on family leave is a subset of that utilized by Ruhm \& Teague (1995) and was originally compiled from the International Labour Office's Legislative Series, their $1984 \mathrm{global}$ survey on "Protection of Working Mothers", and from Social Security Programs Throughout the World, which is published approximately biennially by the U.S. Social Security Administration.

Parental leave is defined to include entitlements to time away from work to care for infants or young children with dismissal prohibited during pregnancy and job-reinstatement guaranteed at the end of the leave. ${ }^{24}$ Employment-protection is required because it is a key characteristic of family leave policies which are viewed as a benefit from the perspective of workers. As discussed, many nations which had previously enacted compulsory "maternity protection" laws added job-security provisions during the period covered by the data.

23 For example, fewer than $1 \%$ of Germans receiving family leave benefits in 1989 were men (Der Bundesminister fuer Jugend, Familie, Frauen und Gesundheit, 1989). I thank Katharina Spiess for providing me with and translating this information.

${ }^{24}$ Ruhm and Teague (1995) coded Spain as providing 156 weeks of total leave beginning in 1970 , as compared to 52 weeks in the present analysis. This change was made because job-protection is guaranteed for only one year, although women are entitled to preferential reinstatement if they return within a three year period. 
Paid leave refers to supplements which are directly related to previous earnings, as opposed to social insurance payments available to individuals independent of their employment histories. A distinction is made between paid and total leave entitlements, where the latter include rights to unpaid time off work. In practice, however, it may be difficult to distinguish between unpaid leave which is guaranteed by law and similar work absences which are granted by employers but not mandated. Furthermore, the actual use of lengthy leave entitlements may be quite limited when payment is not provided. For these reasons, the analysis focuses primarily on rights to paid time off work. Finally, no attempt is made to model wage replacement rates or to separately account for leave available only to the mother, as compared to that which can be taken by either parent.

The leave durations apply to persons meeting all eligibility criteria. This overstates actual time off work, since some individuals will not fulfill the employment requirements while others will use less than the entire allowed absence. ${ }^{25}$ In most countries, qualifying conditions either have not changed or have loosened over time and increased labor force participation should allow more women to meet given employment history requirements. Therefore, a greater proportion of females are expected to qualify for benefits at the end of the period than at the beginning, implying that the secular increase in family leave entitlements is understated. ${ }^{26}$

The dependent variables are (natural logs of) employment-to-population ratios, weekly work hours, and hourly wage rates. Data on EP ratios are from various issues of the OECD publication Labour Force Statistics. Those on hours and wages are from several volumes of the ILO Yearbook of Labor Statistics. Work hours refer to manufacturing employment, with information disaggregated by sex available for 9 of the 16 countries. ${ }^{27}$ Gender-specific wage

25 In rare cases, workers receive longer leave due to voluntary agreements with employers. 26 There are also substantial differences in leave "take-up rates", which are beyond the scope of this analysis to explain or account for.

27 Data were not obtained for Austria, Belgium, Denmark, Finland, France, Italy, and Portugal. 
data were obtained for 12 nations and refer to either manufacturing or all non-agricultural workers. ${ }^{2 \theta}$ Nominal wages were deflated by purchasing power parities, using OECD National Accounts data, and by the U.S. Consumer Price Index. Age-specific information on the EP ratios of women aged $25-34$ and 45-54 was also obtained for 9 nations. ${ }^{29}$ Finally, population (of civilians aged 15-64) and birth rate (per 1000 resident population) data were obtained from various issues of Labor Force Statistics.

The data are not always completely comparable either between or within countries. For example, purchasing power parities provide the best method of adjusting nominal wages but are unlikely to supply exactly equivalent information across time and place. Similarly, nations sometimes alter their methods of collecting or aggregating the data. The estimation strategy was designed to minimize biases resulting from such noncomparabilities. In particular, after including vectors of country and year dummy variables, most of the analysis focuses on gender differences in labor market outcomes. This automatically accounts for the effects of breaks in data series which affect the information on men and women equally. To insure that this condition is met, the ratio of (the log of) female to male outcomes was examined for periods immediately preceding and following each interruption in series. In the few instances where a disproportionate impact was observed, missing values were entered for the period either before or after the break. ${ }^{30}$

28 Wages refer to non-agricultural workers for Belgium, Denmark, Germany, and Switzerland and to manufacturing employees for Finland, France, Greece, Ireland, the Netherlands, Norway, Sweden and the UK. Information is missing for Austria, Italy, Portugal, and Spain. 29 These include Finland, France, Germany, Ireland, Italy, Portugal, Spain, Sweden, and Great Britain. The data for Italy refer to $25-39$ and $40-49$ year olds.

30 Specifically, in order to maximize the variation in observed parental leave policies, observations were deleted for the period with no change (or less change) in leave durations. 


\section{Time-trends and Correlates of Parental Leave}

Parental leave entitlements increased sharply between 1969 and 1988 . Weighting observations by the country's working age population, the average duration of total leave rose from 15 to 57 weeks and that for paid leave increased from 10 to 32 weeks (see 2a).

Conversely, as shown in figure $2 b$, the (weighted) percentage of the population employed declined slightly (from $64 \%$ to $62 \%$ ), as a moderate increase for women (from $45 \%$ to $50 \%$ ) was more than offset by a substantial decline for men (from $86 \%$ to $73 \%$ ). ${ }^{31}$ As expected, wages rose dramatically over time (see figure $2 \mathrm{c}$ ). More importantly, the gender gap in log earnings fell rapidly at the beginning of the period (from .43 in 1969 to .31 in 1977) but relatively little thereafter (declining to .29 by 1988).

Table 1 details the parental leave provisions effective in 1988, the last year of the data. At that time, the 16 countries offered a minimum of 10 weeks of paid leave, with 12 nations mandating entitlements of 12 to 18 weeks and 3 (Finland, Germany, and Sweden) requiring rights to more than a year off work. Over half the nations allowed additional absences without pay, although in only 5 countries (Austria, France, Norway, Spain, and the United Kingdom) was the unpaid leave substantial. ${ }^{32}$ Fathers were eligible to a portion of the time at home in 9 of the 16 countries. ${ }^{33}$ The conditions required to qualify for leave varied but persons with more than a year of service were usually covered.

31 The fall in EP ratios partially results from the secular increase in European unemployment. 32 Unpaid leave, when provided, is always in additional to paid entitlements. Thus, durations of paid and total leave are virtually identical at short or moderate durations of the latter, with substantial divergences occurring only when total leave allowances exceed six months.

${ }^{33}$ Leave durations have continued to lengthen since the end of the sample period. For instance, in January 1995, the entitlement was three years in Finland, France, and Germany and two years in Austria (Organization for Economic Cooperation and Development, 1995). Ondrich, et. al. (1995) analyze the effects of recent changes in German leave regulations on the return to work after childbirth. 
Table 2 provides information on the levels and changes in total and paid leave in each country across time. The number of nations providing some type of parental leave entitlement rose from 8 in 1969 to 13 in 1979, with all 16 doing so in 1988. Most countries supplying family benefits in 1969 extended them during the sample period, with the result that the dispersion of leave durations increased over time.$^{34}$ Some nations lengthened entitlements more than once during the 20 years while others did so in a single increment.

The correlates of parental leave were briefly examined by estimating the equation:

$$
L_{i t}=X_{i 1}^{\prime} \alpha+\varepsilon_{j 11}
$$

where $L$ is the number of weeks of leave in country $j$ at year $t, X$ a vector of covariates (hourly wages, birthrates, total and female EP ratios, total and female unemployment rates), $\varepsilon$ a disturbance term, and observations were weighted to adjust for heteroscedasticity using the procedure discussed in the next section. Ceteris paribus, leave durations were increasing in wages, the percentage of women employed, and female unemployment rates while declining with overall EP ratios and joblessness. Birth rates were positively correlated with total leave durations but either negatively related to or independent of paid time off work. ${ }^{35}$

\section{Estimation Strategy}

Labor market outcome $Y$ (measured in natural logs) for group $i$ in country $j$ at year $t$ is assumed to be determined by:

$$
Y_{i j l}=a_{i j}+b_{i t}+c_{j i}+L_{i t}{ }^{\prime} d_{i}+e_{i j t}
$$

34 The standard deviation of weighted total (paid) durations was 16.6, 34.8, and $57.9(8.7 .14 .2$, and 22.4 ) weeks in 1969, 1979, and 1989, respectively. The difference between minimum and maximum entitlements was 65,120 , and $108(36,54$, and 62) weeks in the same years.

35 A table showing these results is available upon request. The findings are consistent with family leave being a normal good, which is restricted when overall job competition increases but becomes more available when women account for a greater proportion of the labor force and have particular difficulties exiting unemployment. The negative relationship between birthrates and paid leave may reflect pronatalist strategies during periods of slow population growth, whereas the positive coefficient for total leave could indicate political pressure to lengthen the entitlements when many women are having children. 
where $L_{j i}$ is the leave entitlement, $a_{i j}$ a group-specific country fixed-effect, $b_{i 1}$ a group-specific time-effect, $c_{i j}$ a time-varying country effect, and $e_{i, j}$ is a white noise disturbance. The subscripts $m$ and $f$ hereafter denote males and females.

Since women use almost all weeks of family leave, it is assumed that leave entitlements only affect female labor market outcomes (i.e. $d_{m}=0$ ). Thus, we obtain:

$$
\begin{aligned}
& Y_{m j l}=a_{m j}+b_{m l}+c_{j i}+e_{m j l 1} \\
& Y_{j l}=a_{i j}+b_{n}+c_{j 1}+L_{j l} d_{1}+e_{f j l} .
\end{aligned}
$$

Difference-in-difference (DD) models of the form:

$$
Y_{i j l}=\alpha_{i j}+\beta_{i l}+L_{j 1} \delta_{i}+\varepsilon_{i j 1}
$$

investigate within-country changes in the dependent variable as a function of variations in leave durations. $\hat{\delta}$ provides an unbiased estimate of the leave effect if $\varepsilon_{\mathrm{ijl}}$ and $\mathrm{L}_{\mathrm{jl}}$ are uncorrelated. Since $\varepsilon_{\mathrm{ij} 1}=c_{\mathrm{ji}}+\mathrm{e}_{\mathrm{ij} t}$, this requires $\mathrm{L}_{\mathrm{jl}}$ and $c_{\mathrm{jl}}$ to be orthogonal. Bias is introduced if time-varying country effects are correlated with changes in parental leave (e.g. if the political process leads countries to increase entitlements when employment is rising) ${ }^{36}$

If $d_{m}=0$, this bias can be easily eliminated. Notice that:

$$
Y_{j i}-Y_{m j t}=\left(a_{i j}+b_{f t}+c_{j 1}+L_{j l}{ }^{\prime} d_{i}+e_{f i}\right)-\left(a_{m j}+b_{m t}+c_{j l}+e_{m j i}\right)
$$

or equivalently

$$
\Delta Y_{j 1}=\Delta a_{i}+\Delta b_{1}+L_{j i} d_{1}+\Delta e_{j 1}
$$

Since $c_{j 1}$ has been differenced away, consistent estimates of the parental leave parameter are obtained from difference-in-difference-in-difference regressions of the form:

$$
\Delta Y_{j 1}=\alpha_{j}+\beta_{i}+L_{j i}{ }^{\prime} \delta+\varepsilon_{j i}
$$

The DDD estimates measure how growth in the gender gap in labor market outcomes varies as a function of changes in leave entitlements.

${ }^{36}$ A direct estimate of the bias caused by time-varying country effects can be obtained from the parental leave coefficient in the DD model for male labor market outcomes. 
If family leave also influences male outcomes $\left(d_{m} \neq 0\right)$, the DDD estimate of $\hat{\delta}$ supplies a consistent estimate of $\left(d_{r}-d_{m}\right)$, rather than of $d_{r}$. Thus, if $d_{1}$ and $d_{m}$ have the same sign, the regression coefficient provides a downwards biased estimate of $d_{1}$. Since men account for only a tiny fraction of the time taken off work in most countries, however, the resulting bias is likely to be small. For instance, if $d_{r}$ and $d_{m}$ are proportionate the weeks of leave used by each sex, the understatement will be approximately $8 \%$ in a country (such as Sweden) where men use $7 \%$ of the leave and $2 \%$ in a nation where males account for $2 \%$ of total weeks. ${ }^{37}$ Conversely, $d_{1}$ and $d_{m}$ have the opposite sign (e.g. if companies or households respond to lengthened entitlements by substituting employment away from females and towards males). ${ }^{38}$ In this case, $\hat{\delta}$ provides an upper bound estimate of $d_{t}$.

The DDD procedure above accounts for all time-varying factors whic. affect both sexes equally. However, the estimates may still be inconsistent if there are sex-specific time-varying effects. This can be seen by replacing the $c_{\mathrm{jt}}$ term in (2) with $c_{\mathrm{ij} 1}$. Equation (5') then becomes:

$$
\Delta Y_{j 1}=\Delta a_{j}+\Delta b_{1}+\Delta c_{j 1}+L_{j 1}{ }^{\prime} d_{1}+\Delta e_{j 11}
$$

where $\Delta c_{j l}=c_{w j i}-c_{m j i} ; \hat{\delta}$, obtained from (6), is then biased if $E\left(L_{j t} \mid \Delta c_{j l}\right) \neq 0$.

Omitted explanatory variables represent a potentially important potential source of sex-specific time-varying factors. ${ }^{39}$ This source of confounding can be reduced by estimating models which include a vector of country-specific time-trends $\left(T_{j}^{\prime}\right)$ of the form:

$$
\Delta \mathrm{Y}_{\mathrm{jl}}=\alpha_{\mathrm{i}}+\beta_{\mathrm{l}}+\mathrm{T}_{\mathrm{j}}^{\prime} \gamma+L_{\mathrm{jt}}{ }^{\prime} \delta+\varepsilon_{\mathrm{jl}}
$$

${ }^{37}$ Let the $p$ and $1-p$ represent the proportion of weeks of leave taken by men and women respectively. By assumption, $d_{m}=\pi d_{l}$, for $\pi=p /(1-p)$, which implies that $d_{f}=\delta /(1-\pi)$. Thus, if $p=.07, \pi=.0753$ and $1 /(1-\pi)=1.0814$. Similarly, if $p=.02, \pi=.0204$ and $1 /(1-\pi)=1.0208$.

${ }_{38}$ Similarly, firms might replace women of childbearing ages with older females.

39 For instance, if the education of women rises relative to men, in countries extending leave durations, parental leave could be positively related to (relative) female employment and earnings due to the increases in schooling, rather than because of the leave mandates. 
Equation (7) eliminates the biases associated with changes in sex differentials in the omitted characteristics, to the extent the latter follow the specified time trend.

To adjust for heteroscedasticity resulting from differences in population sizes, the models are estimated by weighted least squares. The weights used are equal to the (square root of the) inverse of the predicted values obtained from regressions of the squared OLS residuals on a constant term and the reciprocal of the working age population for the specific country-year observation. ${ }^{40}$

\section{DDD Estimates: An Illustrative Example}

The advantages of the DDD methodology can be illustrated with the following example. Countries are placed in the experimental (nonexperimental) group at time $t$ if they have (have not) increased the duration of paid leave since the previous year. Average EP ratios, with observations weighted by country-year working age populations, are then compared for period $\mathrm{t}-1$ (before the potential change) and $\mathrm{t}+1$ (after it). This descriptive analysis corresponds to the econometric estimates which follow with two exceptions. First, the experiment examines whether or not countries have modified leave entitlements but does not account for the size of any adjustments. Second, changes in employment rates are calculated over just two time periods, rather than for multiple years.

The top panel of Table 3 displays DD results for males and females together. EP ratios decline by $0.428 \%$ in the nonexperimental countries, between $t-1$ and $t+1$, but grow by $0.300 \%$ in the experimental nations. This suggests that increases in paid leave are associated with a $0.728 \%$ rise in the percentage-of the-population employed. However, as illustrated in the bottom panel of the table, the higher employment need not be caused by the extension in leave

40 As shown by Blackburn (1995), this procedure is more efficient than weighting by (the square root of) population size if there is a common group effect (or group-time interaction) across individuals in a country. The significant constant term obtained in virtually all of the regressions on squared residuals confirms that such group effects are important. 
but rather could result from unobserved confounding factors. Notice that the increase in relative job-holding is greater for men $(0.977 \%)$ than for women $(0.494 \%)$, even though parental leave policies are expected to have little or no effect on the male labor market. Calculating the "true" parental leave effect as the difference between changes in female and male outcomes provides the DDD estimate of $-0.483 \%(0.494 \%-0.977 \%)$. This suggests that increases in paid leave reduce female EP ratios and that countries extend the entitlements during periods of rising relative employment.

\section{Econometric Results}

Table 4 displays econometric estimates of the relationship between parental leave and the three labor market outcomes. Vectors of country and time dummy variables are included, so these represent difference-in-difference estimates. The equations are estimated separately for males and females, with the samples restricted to cases where data on the dependent variable are available for all specifications. Observations are weighted as discussed above to adjust for heteroscedasticity. The parental leave regressor in the top (bottom) panel of the table is weeks of total (paid) leave divided by 100 .

The leave coefficients are of roughly similar magnitude for men and women in all models and durations are statistically significantly related to male labor market outcomes in two of the six cases (i.e. paid leave on EP ratios and work hours). In only one specification (total leave on work hours) is a significant effect obtained for women but not men and, even in this case, the disparity in the estimated effect is small. These results further suggest that countries extend rights to paid leave during periods of robust employment growth and that bias is introduced if this source of confounding is not accounted for. ${ }^{41}$ To the extent that the regressions on male outcomes pick up the effects of unobserved confounding factors, they indicate that family leave

41 Klerman \& Leibowitz (1995) obtain similar results for state mandates in the United States. 
entitlements have a smaller (in absolute value) impact on women's employment and work hours than are implied by the DD estimates in the first row of each panel. Therefore, the remainder of the analysis focuses on DDD specifications, which include a comparison group (men) whose labor market outcomes are expected to be largely unaffected by changes in leave legislation.

\subsection{DDD Estimates}

Table 5 summarizes a first set of DDD estimates examining the effects of paid leave. In each equation, the dependent variable is the difference between (the log of) female and male labor market outcomes. PAID indicates weeks of paid leave (divided by 100), with a quadratic term included to allow for nonlinearities in the estimated effect. The P-Value refers to the null hypothesis that all of the parental leave variables included in the specified model (PAID and its square in these regressions) are jointly equal to zero. All equations include vectors of year and country dummy variables. The lower panel of the table shows the estimated impact of specified entitlements to paid leave on the dependent variable, compared to the case of no mandate.

Specification (a) is the basic DDD model. The birthrate is included as an additional covariate in model (b), to allow for the possibility that the number of children influences labor market involvement and is correlated with leave entitlements. However, since some countries use parental leave policies as part of a strategy to raise the birthrate, the latter may be endogenous and its inclusion as an explanatory variable problematic. Parental leave mandates could also influence labor market outcomes with a lag. ${ }^{42}$ To allow for this, specification (c) includes controls for paid leave (and its square) at year $t-1$, as well as at time $t$, with the table displaying the sum of the coefficients at $\mathrm{t}-1$ and $\mathrm{t}$, along with the corresponding standard error.

42 Most obviously, this may occur because policy changes often take effect in the middle of calendar years. Since this study uses annual data, only a portion of the total impact will therefore be observed during the year of enactment. 
These regressions provide little evidence that paid leave is related to either EP ratios or hourly wages. Although the point estimates suggest that intermediate durations modestly increase female employment while rights to extended work absences reduce relative wages, neither effect approaches statistical significance. By contrast, paid leave is strongly positively associated with weekly work hours. For instance, legislation guaranteeing nine months off work with pay is predicted to increase hours by $2 \%{ }^{43}$

These results are relatively unaffected by the inclusion of controls for birthrates or lagged leave durations. As shown in specification (b), the addition of birthrates reduces (increases) the predicted effect of paid leave on EP ratios (hourly wages), but the change is small in both a statistical and an economic sense, while having essentially no impact on work hours. ${ }^{44}$ Likewise, the predicted parental leave effects are robust to the inclusion of lags. For instance, the differential assuciated with 20 weeks of paid leave, compared to no entitlement, is $0.8 \%, 1.3 \%$, and $-0.7 \%$ for EP ratios, work hours, and hourly wages, when lags are included in the model (column (c)), versus $0.9 \%, 1.3 \%$, and $-0.4 \%$ when they are not (specification (a)). ${ }^{45}$ Given these findings, birthrates and lagged durations are excluded from the econometric estimates presented in the remainder of the paper.

\subsection{DDD Estimates With Time-trends}

The DDD estimates above may be biased if there are sex-specific time-varying country-effects which are correlated with changes in leave entitlements. The models presented in Table 6 reduce this potential source of confounding by adding a vector of country-specific

43 However, as shown below, this finding is not robust to the addition to the model of country-specific time-trends.

44 Birthrates are significantly negatively related to employment, hours, and wages.

45 To avoid reducing the sample size, leave data for 1968 are also used in specification (c). I also estimated models with leave at year $\mathrm{t}, \mathrm{t}-1$, and $\mathrm{t}-2$ controlled for. The second lag was never statistically significant and the results were similar to those with just a one year lag. 
time-trends to the set of covariates. Other than this change, specification (a) is identical to column (a) of Table 5.

The inclusion country-specific time-trends dramatically alters the estimated impact of parental leave mandates. The predicted effect of paid leave switches from small and insignificant to substantially positive and statistically significant when considering EP ratios and from significantly positive to having no impact for work hours. For example, rights to 36 weeks of paid leave increase predicted female employment by $5.3 \%$ and hours by $-0.2 \%$ in specification (a) of Table 6 , as compared to $0.9 \%$ and $1.9 \%$ in model (a) of table $5 .{ }^{46}$

These findings suggest that countries raise paid leave entitlements in periods when the relative employment rates (work hours) of women are trending down (up). When combined with the DD estimates summarized in Table 4, they show that the adoption or extension of parental leave guarantees is endogenous and follows a fairly complicated pattern -- leave durations are typically lengthened when overall employment is rising (relative to other countries) but women's job-holding is falling (relative to men).

Continuous regressors may poorly capture the effects of the parental leave mandates, even when quadratic or higher order terms are included. ${ }^{47}$ For example, the effect of legislating entitlements to short work absences could have substantial effects, while further extensions of the leave period could have little or no additional impact. ${ }^{48}$ The models above would then be

46 I experimented with including a vector of quadratic country time-trends in the model. The results obtained were quite similar to those using a linear trend. As an additional specification check, the models were estimated with parental leave (and its square) at year $t+1$ controlled for. The lead leave variables never approached statistical significance in the specifications which included country time-trends but were jointly significant for the hours equation in their absence. This last result provides a further indication of the importance of including controls for country-specific time-trends.

47 The equations were also estimated using cubic leave specifications. These yielded results which were generally very similar to those discussed above.

${ }^{48}$ For instance, this might occur if women strongly desire to be at home for a short period following childbirth, with rapidly diminishing marginal utility of additional time off the job. 
misspecified since they restrict the consequence of an initial (arbitrarily short) period of leave to be small, relative to that of longer durations. To permit this type of "step" effect, the dummy variable ANYPAID was added to the models displayed in specification (b) of Table 6. ANYPAID takes the value one if the country has enacted a leave mandate and zero otherwise. It therefore indicates the impact of paid job absences of arbitrarily short duration. ${ }^{49}$ In these specifications, PAID and its square then show the effects of extending an existing leave mandate.

The coefficient on ANYPAID is highly significant for EP ratios and work hours and is of substantial size and has a T-statistic exceeding one for hourly wages. The point estimates indicate that legislation requiring employers to offer minimal amounts of paid leave raise the relative employment, hours, and wages of women by $2.5 \%, 2.8 \%$, and $1.7 \%$ respectively. The predicted impact of further extending the leave period is summarized in the lower panel of Table 6 and is detailed in Figure 3. Interestingly, whereas EP ratios are predicted to increase through approximately the first year of paid leave, fairly sizable declines in expected work hours and wages are observed at longer durations. For instance, entitlements to 10 weeks away from work change predicted employment, hours, and wages by $3.4 \%, 1.1 \%$, and $0.1 \%$, while the corresponding impact of 36 weeks of paid leave is $4.6 \%,-2.0 \%$, and $-1.8 \%$. Also notice that the effect on hours is highly significant, in contrast to the results in column (a), while that on wages still does not quite reach statistical significance.

Table 7 provides results for additional specifications which include categorical leave variables. In column (a), the only leave regressor is ANYPAID, the dummy variable distinguishing between no leave entitlement and rights to some time off work with pay. Model (b) contains dichotomous variables indicating paid leave in the ranges of $1-13,14-26$, and >26

49 Since the initial period of leave is paid for all countries in this sample, this variable is identical to one which distinguishes between some versus no total leave. 
weeks, with 0 weeks the excluded reference category. ${ }^{50}$ Finally, specification (c) incorporates dummy variables indicating the same three duration categories as column (b) but controlling for total (paid and unpaid) rather than just paid leave.

The findings of the table can be summarized as follows. First, parental leave has a positive effect on women's employment, with somewhat larger gains for rights to intermediate or long than for short periods away from the job. These estimates are similar to those obtained previously. For instance, $1-13,14-26$, and $>26$ weeks of paid leave lead to $2.7 \%, 4.3 \%$, and $4.6 \%$ increases in the predicted female EP ratio (see model (b)), as compared to $3.4 \%, 4.1 \%$, and $4.6 \%$ changes for durations of 10,20 , and 36 weeks in column (b) of Table 6.

Second, there is some indication that brief leave entitlements increase work hours but little evidence of effects at longer durations. This contrasts with a negative impact of rights to lengthy leave in column (b) of Table 6 . However, there is some reason to suspect that the specification in the earlier table may be preferred. ${ }^{51}$ More generally, the sensitivity of the findings to the choice of models implies that the results for work hours should be interpreted cautiously.

Third, the categorical specifications suggest that rights to short work absences may raise (and certainly do not reduce) predicted wages, whereas women pay for lengthy paid entitlements by receiving lower earnings. Thus, $1-13,14-26$, and $>26$ weeks of paid leave are associated with wage differentials of $1.1 \%,-1.5 \%$, and $-2.9 \%$, compared to the reference group, with the null hypothesis of no wage effect strongly rejected. There is also some indication that short periods of total leave raise wages relative to either no entitlement or rights to a longer period off work (see column (c)).

50 The results are not sensitive to changing the ranges of the categorical variables.

51 These include the relatively high standard errors on the leave coefficients in Table 7 and the higher adjusted R-Squared in column (b) of Table 6 than for any of the three models shown in the subsequent table. 


\subsection{DDD Estimates For Women of Different Ages}

Up to this point, men have been used as the comparison group, to account for time-varying country-specific factors which may be correlated with parental leave durations The inclusion of country time-trends provided one method of reducing potential biases which might result from sex-specific time-varying country effects (e.g. those introduced if nations increase leave durations during periods of slow growth in relative female employment). As a complementary approach, this section compares the EP ratios of 25-34 year old women to those of their counterparts aged $45-54 .^{52}$ Since $25-34$ year old females are in their prime childbearing years, they are expected to be directly and strongly affected by parental leave mandates. Conversely, 45-54 year olds have completed virtually all of their fertility and so may be less influenced by the statutes. Thus, the natural experiment involves contrasting changes in the percentage of the younger and older cohorts of women employed, as a function of variations in leave entitlements.

Table 8 summarizes the econometric estimates. The dependent variable in all models is the difference in (the log of) the EP ratio of 25-34 year old females versus those of women aged 45-54. Vectors of time and year dummy variables are also included, to provide DDD estimates, as are country-specific time-trends. Observations are weighted to correct for heteroscedasticity, using the procedure discussed above. The five specifications correspond to the models estimated in Tables 6 and 7 . Thus, column (a) shows results for the quadratic in weeks of paid leave (divided by 100); model (b) adds the leave/no leave dummy variable; ANYPAID is the only parental leave regressor in specification (c); and columns (d) and (e) include controls for categorical variables indicating ranges of paid and total leave durations.

52 Age-specific data on female work hours or wages are not readily available, precluding analysis of these outcomes. 
The table confirms that parental leave entitlements raise the employment of young women. The large and significant coefficient on ANYPAID in model (b) implies that regressions which include only continuous leave variables are misspecified and indicates that leave legislation of even short duration substantially increases relative EP ratios. Thus, in column (c), the existence of paid leave legislation is predicted to raise the percentage of 25-34 year old women employed by $9.0 \%$, relative to $45-54$ year olds. Conversely, there is no consistent prediction concerning the additional effect of more extended leave entitlements -- the impact is estimated to be positive in specifications (a) and (b), negative in model (e), and with no clear pattern in column (d) -- with all of the effects estimated imprecisely.

\subsection{Discussion}

The preceding analysis indicates that parental leave legislation increases the employment-to-population ratios of women, especially those of childbearing age. However, the data also raise the possibility that firms respond to lengthy leave entitlements by reducing the work hours of females and more strongly suggest that women pay for rights to extended paid leave by receiving lower earnings. This pattern of results makes sense. Short periods of parental leave are likely to impose few costs on employers but could confer substantial benefits to workers, with the consequence that employment increases without negative wage effects. For instance, firms may be able to temporarily reassign individuals to fulfill the responsibilities of absent employees and rights to brief time away from the job, by allowing return to the old position following childbirth, may increase the ability of women to retain firm-specific investments. Conversely, lengthy entitlements are likely to be costlier to companies but may fail to provide sufficient compensatory benefits to workers and could lead to the depreciation of human capital, with the result that wages decline. 
One issue deserving mention is that many European countries count individuals on parental leave as "employed but absent from work", rather than "not employed". Reported EP ratios will therefore rise when countries expand leave entitlements, to the extent that the work absences of "employed" persons increase. Some indication of the relative size of this effect can be obtained by noting that $0.9 \%$ of women's "employment" in $12 \mathrm{EC}$ countries was accounted for by maternity leave in 1983 (OECD, 1995). ${ }^{53}$ By comparison, leave mandates are predicted above to raise EP ratios by $4 \%$ to $5 \%$. Thus, the estimated effects of the legislation are large compared to the number of women counted as employed but actually on maternity leave ${ }^{54}$ Moreover, the estimated impact rises only marginally with the duration of leave, in contrast to the more substantial increase which would be expected if the observed "employment" effect were actually caused by changes in leave-taking.

The predicted wage reductions, ranging from $1.5 \%$ to $3 \%$ for laws mandating lengthy (i.e. six months or more of) paid leave, are quite large given that only a limited proportion of women are absent from work for this reason at any one time and since a substantial fraction of the leave benefits are paid by the government, rather than the employers, in most countries. Nevertheless, impacts of this magnitude may be plausible for several reasons. First, only five countries (Denmark, Finland, Germany, Italy, Sweden) had legislated rights to paid leave exceeding six months, during the sample period, and each had relatively high rates of work absence due to maternity leave or personal/family reasons. Second, the expansions in leave

53 Similarly, $0.6 \%$ of female "employment" consisted of absences for other family or personal reasons, including extended parental leave. The $12 \mathrm{EC}$ countries include Belgium, Denmark, France, Germany, Greece, Ireland, Italy, Luxembourg, Netherlands, Portugal, Spain, and the United Kingdom.

${ }^{54}$ Work hours could also be overstated to the extent that individuals take part-time parental leave. However, only a few countries provide a legal right to partial absences and, even when provided, parents seldom take it. For example, among 11 countries (Belgium, Denmark, France, Germany, Greece, Ireland, Luxembourg, Portugal, Spain, Sweden, and the United Kingdom) for which 1988 data were available, part-week absences due to maternity leave were only observed in Britain (Organization for Economic Cooperation and Development, 1991). 
typically occurred relatively late in the time period and coincided with increased use of maternity leave. ${ }^{55}$ Third, employers may incur substantial nonwage costs when the leave entitlements are extremely lengthy. For example, it may become much harder to schedule replacement workers, given considerable uncertainty regarding the actual leave period and the possibility that the individual will ultimately choose not to return to the same job. ${ }^{56}$ These difficulties may be magnified by national regulations which limit the duration of temporary work on fixed-term contracts. Finally, when leave durations exceed one year, women having multiple children relatively close together may be away from their jobs for several years consecutively, or with just brief spells of intervening employment, causing substantial depreciation of human capital.

\section{Conclusion}

Virtually all industrialized countries currently provide women with rights to job-protected maternity leave during the period surrounding childbirth. Some nations (e.g. Germany) have allowed lengthy paid absences for many years whereas others (e.g. the United States) have only recently mandated entitlements to limited periods off work without pay. Despite the widespread international implementation, there has been relatively little research investigating the economic consequences of parental leave. This study helps to fill this gap by examining how leave mandates affect labor market outcomes. One important innovation is the focus on differences between female and male values of the dependent variables. Since women use

55 Denmark extended paid leave durations by 18 weeks in 1981 and 10 weeks in 1987; Finland by 6,8 , and 26 weeks in 1979, 1983, and 1985; Germany by 18,25, and 9 weeks in 1979, 1986, and 1988; Italy by 26 weeks in 1979; and Sweden by 12 weeks in 1979 and 18 weeks in 1985 . In 1992, 4.1\%,3.7\%, and 3.1\% of women's "employment" in Denmark, Germany, and Italy was accounted for by maternity leave or absences for other personal/family reasons, as were $5.5 \%$ of weeks for maternity or parental leave in Sweden, in the same year. (Organization for Economic Cooperation and Development, 1995). These are lower-bound estimates, since some persons on leave do not report themselves as having jobs and so are not included in the employment figures.

56 For instance, less than half of German job leavers return to work at the end of the leave period (Organization for Economic Cooperation and Development, 1995). 
virtually all parental leave in most countries, changes in entitlements are likely to have little or no effect on men, making them a natural comparison group. Limited analysis is also provided of how the employment of women of childbearing ages varies, relative to that of older females, as a function of parental leave.

Rights to paid time off work raise the percentage of women employed, with a substantial effect observed for even short durations (i.e. less than 3 months) of guaranteed work absence. Based on the preferred econometric specifications, a reasonable estimate is that leave legislation increases the employment-to-population ratio of all females by around $4 \%$ and of women of childbearing age by approximately $9 \%$, with up to a quarter of this change resulting from increased leave-taking by "employed" women. By contrast, the mandates have weaker and less consistent effects on work hours. More generally, the econometric estimates exhibit considerable sensitivity to the choice of models, with evidence presented of the importance of controlling for both time-varying country effects and sex-specific within-country time-trends. This fragility highlights the importance of choosing the "right" specification and points to potential shortcomings of much of the previous related research.

A second issue addressed is whether employers pass the costs of the (largely group-specific) leave benefit through to women in the form of lower relative wages. Short periods of leave are found to either have no effect on or to raise female earnings. Conversely, lengthier paid entitlements are associated with substantial wage reductions, with predicted decreases in the range of $1.5 \%$ to $3 \%$ for durations of six months or more. Extended parental leave is sometimes justified on the grounds that, even if it decreases efficiency, it is desirable because it improves the position of women in the workplace. However, the evidence that females pay for the rights through reduced wages raises questions about this equity argument. 
To summarize, the employment of women appears to be increased by even relatively short (less than 6 months) durations of paid leave, whereas their relative wages may fall with more extended entitlements. This suggests that the work absences currently guaranteed in many European countries may be so lengthy as to reduce the earnings of females. Conversely, there is little indication that substantial costs would be incurred, in the U.S., if the period of parental leave were modestly extended or if payment were provided. ${ }^{57}$

These conclusions should be viewed as tentative for a variety of reasons. First, the sample sizes are relatively small, resulting in imprecise estimates of parental leave effects in some models. Second, the data on leave are incomplete. A more comprehensive investigation would include information on the percentage of workers in each country qualifying for the benefit, the "take-up rate" among qualified individuals, and details on the structure of paid entitlements. Third, other efficiency benefits or costs may be associated with the mandates. Most significantly, it is often argued that parental leave improves the health and well-being of children. This represents an important area for future research.

57 However, as noted above, no European country offers unpaid leave, except as an addition to an initial period of paid time off work, making it difficult to apply these results to the United States which, under the FMLA, mandates only unpaid leave. 


\section{References}

Addison, John T. and W. Stanley Siebert (1993) Current Controversies, No. 6: Social Engineering in the European Community: The Social Charter, Maastricht and Bevond, London: The Institute of Economic Affairs.

Aghion, Phillipe and Benjamin Hermalin (1990) "Legal Restrictions on Private Contracts Can Enhance Efficiency" Journal of Law, Economics, and Organization, 6(2), 381-409

Anderson, Patricia M. and Bruce Meyer (1995) "The Incidence of A Firm-Varying Payroll Tax: The Case of Unemployment Insurance", National Bureau of Economic Research Working Paper No. 5201.

Blackburn, McKinley L. (1995) "Misspecified Skedastic Functions for Grouped-Data Models", mimeo, University of South Carolina.

Blank, Rebecca M. (1994) Social Protection Vs. Economic Flexibility. Chicago: University of Chicago Press.

Bookman, Ann (1991) "Parenting Without Poverty: The Case for Funded Parental Leave," in Hyde and Essex, Parental Leave and Child Care (pp. 66-89). Philadelphia, PA: Temple University Press.

Brocas, Anne-Marie, Anne-Marie Cailloux and Virginie Oget (1990) Women and Social Security: Progress Towards Equality of Treatment, Geneva: International Labour Office.

Bravo, Ellen (1991) "Family Leave: The Need for a New Minimum Standard" in Hyde and Essex, Parental Leave and Child Care (pp. 165-175). Philadelphia, PA: Temple University Press.

Bundesminister fuer Jugend, Familie, Frauen und Gesundheit. (1989) Erziehungsgeld, Erziehungsurlaub und Anrechung von Erziehungszeiten in der Rentenversicherung, Band 243. Berlin: Verlag W. Kohlhammer, 53. (The Federal Ministry of Youth, Family and Health. (1989) Child Rearing Benefit, Parental Leave and Credits for Rearing Children in the Social Security System, Vol. 243. Berlin: W. Kohlhammer, 53).

Carnegie Task Force on Meeting the Needs of Young Children (1994) Starting Points: Meeting the Needs of Young Children. New York, N.Y.: Carnegie Corporation of New York.

Dalto, Guy C. (1989) "A Structural Approach to Women's Hometime and Experience-earnings Profiles: Maternity Leave and Public Policy," Population Research and Policy Review, 8(3), 247-266.

Frank, Meryl and Robyn Lipner (1988) "History of Maternity Leave in Europe and the United States," in Zigler and Frank The Parental Leave Crisis (pp. 3-22) New Haven: Yale University Press.

Gruber, Jonathan (1994) "The Incidence of Mandated Maternity Benefits," American Economic Review, 84(3), 622-41. 
Gruber, Jonathan and Alan B. Krueger (1991) "The Incidence of Mandated Employer-Provided Health Insurance: Lessons from Workers' Compensation Insurance" in David Bradford (ed.) Tax Policy and the American Economy. Vol. 5 (pp. 111-143). Cambridge, MA: MIT Press.

International Labor Office. (Various Years) Yearbook of Labour Statistics. Geneva: International Labour Office Publications.

International Labor Office. (Various Years) Legislative Series. Geneva: International Labour Office Publications.

International Labor Office (1964) "Protection of Working Mothers: An ILO Global Survey (1964-84)," Women at Work, 2, 1984.

Jacobson, Louis S., Robert J. LaLonde, and Daniel Sullivan. (1993) "Earnings Losses of Displaced Workers" American Economic Review, 83 (September), 685-709.

Kamerman, Sheila B. (1991) "Child Care Policies and Programs: An International Overview," Journal of Social Issues, 47(2), 179-196.

Kamerman, Sheila B. (1988) "Maternity and Parenting Benefits: An International Overview," in Zigler and Frank The Parental Leave Crisis (pp. 235-244) New Haven: Yale University Press.

Klerman, Jacob A. and Arleen Leibowitz. (1995) "Labor Supply Effects of State Maternity Leave Legislation", mimeo, RAND.

Klerman, Jacob A. and Arleen Leibowitz. (1994) "The Work-Employment Distinction Among New Mothers" Journal of Human Resources, 24(2), Spring, 277-303.

Krueger, Alan B. (1994) "Observations on Employment-Based Government Mandates, With Particular Reference to Health Insurance," Working Paper \#323, Industrial Relations Section, Princeton University, January.

Kuhn, Peter (1992) "Mandatory Notice," Journal of Labor Economics, 10(2), 117-137.

Levine, David I. (1991) "Just-cause Employment Policies in the Presence of Worker Adverse Selection," Journal of Labor Economics, 9(3), 294-305.

McGuire, Thomas G. and Christopher J. Ruhm (1993) "Workplace Drug Abuse Policy," Journal of Health Economics 12(1), 19-38.

Mitchell, Olivia (1990) "The Effect of Mandatory Benefit Packages" in Bassi, L., D. Crawford, and R. Ehrenberg (eds.) Research in Labor Economics, Vol. 11. Greenwich, CT: JAI Press, 297-320.

Moeller, Robert G. (1993) Protecting Motherhood: Women and the Family in the Politics of Postwar West Germany, Berkeley, CA: University of California Press. 
Mortensen, Dale T. (1977) "Unemployment Insurance and Job Search Decisions," Industrial and Labor Relations Review, 30(4), 505-517.

Ondrich, Jan, C. Katharina Spiess, Quing Yang. (1995) "Barefoot and in a German Kitchen: Federal Parental Leave and Benefit Policy and the Return to Work After Childbirth in German", prepared for the Ninth Annual Meeting of the European Society of Population Economics, Lisbon, Portugal.

Organization for Economic Cooperation and Development. (1995) "Long-Term Leave for Parents in OECD Countries", in Employment Outlook: July 1995. Paris: OECD Department of Economics and Statistics, 171-202.

Organization for Economic Cooperation and Development. (1991) "Absence From Work Reported in Labour Force Surveys", in Employment Outlook: July 1991. Paris: OECD Department of Economics and Statistics, 177-197.

Organization for Economic Cooperation and Development. (1989) National Accounts, Vol. I: Main Aggregates 1960-1987. Paris: OECD Department of Economics and Statistics.

Organization for Economic Cooperation and Development. (various years) Labour Force Statistics: 1966-1986, 1968-1988, 1971-1991. Paris: OECD, Department of Economics and Statistics.

Rothschild, Michael and Joseph Stiglitz. (1976) "Equilibrium in Competitive Insurance Markets: An Essay on the Economics of Imperfect Information" Quarterly Journal of Economics, 90 , $629-49$.

Ruhm, Christopher J. and Jackqueline L. Teague. (1995) "Parental Leave Policies in Europe and North America" National Bureau of Economic Research Working Paper \#5065, March.

Spalter-Roth, Roberta M. and Heidi I. Hartmann (1990) Unnecessary Losses: Costs to Americans of the Lack of Family and Medical Leave, Washington D.C.: Institute for Women's Policy Research, 1990.

Stoiber, Susanne A. (1990) "Family Leave Entitlements in Europe: Lessons for the United States," Compensation \& Benefits Management, 6(2), Winter, 111-116.

Summers, Lawrence (1989) "Some Simple Economics of Mandated Benefits" American Economic Review, 79(2), 177-83

Trzcinski, Eileen (1991) "Employers' Parental Leave Policies: Does the Labor Market Provide Parental Leave?" in Hyde and Essex Parental Leave and Child Care, (pp. 41-65) Philadelphia, PA: Temple University Press.

U.S. Department of Labor, Bureau of Labor Statistics. (1994) Employee Benefits in Small Private Establishments, Bulletin No. 2441. Washington: U.S. Government Printing Office, May. 
U.S. Department of Labor, Bureau of Labor Statistics. (1993) Employee Benefits in Medium and Large Private Establishments, Bulletin No. 2422. Washington: U.S. Government Printing Office, May.

U S. Social Security Administration. (various years) Social Security Programs Throughout the World. Washington D.C: U.S. Government Printing Office.

Waldfogel, Jane. (1994) "The Family Gap for Young Women in the US and UK: Can Maternity Leave Make a Difference?" mimeo, Columbia University.

Waldfogel, Jane. (1995) "Working Mothers Then and Now: A Cross-Cohort Analysis of the Effects of Maternity Leave on Women's Pay" mimeo, Columbia University.

Waldfogel, Jane (1996) "The Impact of the Family and Medical Leave Act on Coverage, Leave-Taking, Employment and Earnings" mimeo, Columbia University.

Zigler, Edward F., Meryl Frank, and Barbara Emmel. (1988) "Introduction", in Edward F. Zigler and Meryl Frank, eds., The Parental Leave Crisis: Toward a National Policy. New Haven: Yale University Press, $x v-x x v$. 
Table 1: Parental Leave Provisions in 1988

\begin{tabular}{|c|c|c|c|c|}
\hline Country & $\begin{array}{l}\text { Total } \\
\text { Leave }\end{array}$ & $\begin{array}{l}\text { Paid Leave } \\
(\% \text { of pay) }\end{array}$ & $\begin{array}{l}\text { Available } \\
\text { To Fathers }\end{array}$ & Qualification Conditions \\
\hline Austria & 67 wks & 16 wks $(100 \%)$ & None & $\begin{array}{l}10 \text { months of social insurance } \\
\text { coverage in last } 2 \text { years or } 6 \text { months } \\
\text { coverage in last year. }\end{array}$ \\
\hline Belgium & 14 wks & 14 wks $(71 \%)$ & None & 6 months coverage preceding leave. \\
\hline Denmark & $28 w k s$ & 28 wks $(90 \%)$ & 12 wks & $\begin{array}{l}6 \text { months coverage and employment } \\
\text { during previous year, including at } \\
\text { least } 40 \text { hours of work during } 4 \text { weeks } \\
\text { preceding leave. }\end{array}$ \\
\hline Finland & 69 wks & 69 wks $(80 \%)$ & 26 wks & $\begin{array}{l}3 \text { months employment, unless } \\
\text { involuntarily unemployed. }\end{array}$ \\
\hline France & 120 wks & 16 wks $(90 \%)$ & 104 wks & $\begin{array}{l}10 \text { months of insurance prior to leave } \\
\text { and at least } 200 \text { hours of work in } 3 \\
\text { months preveding the pregnancy. }\end{array}$ \\
\hline Germany & 66 wks & $\begin{array}{l}14 \text { wks }(100 \%) \\
52 \text { wks (flat rate) }\end{array}$ & 52 wks & $\begin{array}{l}12 \text { weeks of insurance or } 6 \text { months of } \\
\text { employment. }\end{array}$ \\
\hline Greece & 13 wks & 12 wks $(50 \%)$ & 12 wks & $\begin{array}{l}200 \text { days of employment during last } 2 \\
\text { years. }\end{array}$ \\
\hline Ireland & 18 wks & 14 wks $(70 \%)$ & None & 30 weeks of insurance contributions. \\
\hline Italy & 46 wks & 46 wks $(52 \%)$ & 26 wks & $\begin{array}{l}\text { Insured and employed at start of } \\
\text { pregnancy. }\end{array}$ \\
\hline Netherlands & 12 wks & 12 wks $(100 \%)$ & None & Insured and employed. \\
\hline Norway & 52 wks & 18 wks $(90 \%)$ & 40 wks & $\begin{array}{l}\text { Employed and insured at least } 6 \text { of } \\
\text { the last } 10 \text { months. }\end{array}$ \\
\hline Portugal & 12 wks & 12 wks $(100 \%)$ & 8 wks & Employed with 6 months of insurance. \\
\hline Spain & 52 wks & 14 wks $(75 \%)$ & None & $\begin{array}{l}\text { Insured } 9 \text { months, with } 6 \text { months of } \\
\text { contributions. }\end{array}$ \\
\hline Sweden & 78 wks & 72 wks $(90 \%)$ & 60 wks & Insured 8 months. \\
\hline Switzerland & 14 wks & 10 wks (flat rate) & None & $\begin{array}{l}\text { Up to } 9 \text { months insurance (depending } \\
\text { upon Canton). }\end{array}$ \\
\hline $\begin{array}{l}\text { United } \\
\text { Kingdom }\end{array}$ & 40 wks & 18 wks (flat rate) & None & $\begin{array}{l}6 \text { months of insurance contributions } \\
\text { during previous year and } 2 \text { years of } \\
\text { work with same employer. }\end{array}$ \\
\hline
\end{tabular}


Table 2: Levels and Changes in Parental Leave in Selected Years

Total Leave

\begin{tabular}{|c|c|c|c|c|c|c|c|c|}
\hline \multirow[t]{2}{*}{ Country } & \multirow{2}{*}{$\begin{array}{c}\text { Ave. } \\
\text { Weeks }\end{array}$} & \multirow{2}{*}{$\begin{array}{c}\text { Weeks } \\
\text { in } \\
1969\end{array}$} & \multicolumn{2}{|c|}{$\Delta$ in Weeks: } & \multirow{2}{*}{$\begin{array}{c}\text { Ave. } \\
\text { Weeks }\end{array}$} & \multirow{2}{*}{$\begin{array}{c}\text { Weeks } \\
\text { in } \\
1969\end{array}$} & \multicolumn{2}{|c|}{$\Delta$ in Weeks: } \\
\hline & & & $\begin{array}{c}1969- \\
1979 \\
\end{array}$ & $\begin{array}{c}1979- \\
1988 \\
\end{array}$ & & & $\begin{array}{c}1969- \\
1979 \\
\end{array}$ & $\begin{array}{r}1979 \\
1988 \\
\end{array}$ \\
\hline Austria & 66 & 65 & 2 & 0 & 15 & 12 & 4 & 0 \\
\hline Belgium & 14 & 14 & 0 & 0 & 14 & 14 & 0 & 0 \\
\hline Denmark & 8 & 0 & 0 & 28 & 8 & 0 & 0 & 28 \\
\hline Finland & 34 & 0 & 35 & 34 & 34 & 0 & 35 & 34 \\
\hline France & 73 & 0 & 120 & 0 & 11 & 0 & 16 & 0 \\
\hline Germany & 27 & 14 & 18 & 34 & 27 & 14 & 18 & 34 \\
\hline Greece & 3 & 0 & 0 & 13 & 3 & 0 & 0 & 12 \\
\hline Ireland & 7 & 0 & 0 & 18 & 6 & 0 & 0 & 14 \\
\hline Italy & 45 & 40 & 6 & 0 & 32 & 14 & 32 & 0 \\
\hline Netherlands & 8 & 0 & 12 & 0 & 8 & 0 & 12 & 0 \\
\hline Norway & 36 & 12 & 40 & 0 & 15 & 12 & 6 & 0 \\
\hline Portugal & 10 & 0 & 12 & 0 & 10 & 0 & 12 & 0 \\
\hline Spain & 49 & 0 & 52 & 0 & 13 & 0 & 14 & 0 \\
\hline Sweden & 61 & 36 & 42 & 0 & 50 & 36 & 18 & 18 \\
\hline Switzerland & 13 & 8 & 6 & 0 & 10 & 8 & 2 & 0 \\
\hline United Kingdom & 33 & 18 & 22 & 0 & 18 & 18 & 0 & 0 \\
\hline
\end{tabular}

Paid Leave 
Table 3: Difference-in-Difference-in-Difference Estimates of the Effects of Increases in Paid Leave on the Percent of the Population Employed

\begin{tabular}{|c|c|c|c|}
\hline Group & $\begin{array}{c}\% \text { Employed } \\
\text { Before Increase in } \\
\text { Paid Leave } \\
\left(Y_{\mathrm{t}-1}\right)\end{array}$ & $\begin{array}{c}\% \text { Employed } \\
\text { After Increase in } \\
\text { Paid Leave } \\
\left(Y_{t+1}\right)\end{array}$ & $\begin{array}{c}\text { Time } \\
\text { Difference } \\
\text { for Country } \\
\left(Y_{1+1}-Y_{t-1}\right)\end{array}$ \\
\hline \multicolumn{4}{|l|}{ Males and Females Combined } \\
\hline Experimental Countries & $61.668 \%$ & $61.968 \%$ & $0.300 \%$ \\
\hline Nonexperimental Countries & $62.502 \%$ & $62.074 \%$ & $-0.428 \%$ \\
\hline $\begin{array}{l}\text { Country Difference at a } \\
\text { Point in Time: }\end{array}$ & $-0.834 \%$ & $-0.106 \%$ & \\
\hline Difference-in-Difference: & \multicolumn{2}{|c|}{$0.728 \%$} & \\
\hline
\end{tabular}

Treatment Group: Females

Experimental Countries

Nonexperimental Countries

Country Difference at a Point in Time:

Difference-in-Difference:

Control Group: Males

Experimental Countries

Nonexperimental Countries

Country Difference at a Point in Time:

Difference-in-Difference:
$45.412 \%$

$45.878 \%$

$46.488 \%$

$1.076 \%$

$0.582 \%$

\begin{tabular}{cr}
$-0.466 \%$ & $0.028 \%$ \\
\hline & $0.494 \%$
\end{tabular}

$78.267 \%$

$77.715 \%$

$-0.552 \%$

$79.502 \%$

$77.973 \%$

$-1.529 \%$

Difference-in-Difference-in-Difference:

Note: Cells contain the weighted average employment percentages for the group identified. Experimental Countries are those raising the paid leave entitlement during the calendar year $t$ $(n=23)$; nonexperimental countries are those not changing the duration of paid leave in year $t$ $(n=214)$. 
Table 4: Difference-in-Difference Estimates of Parental Leave Effects

\begin{tabular}{lccc} 
Group & $\begin{array}{c}\text { Employment/ } \\
\text { Population }\end{array}$ & $\begin{array}{c}\text { Weekly } \\
\text { Work Hours }\end{array}$ & $\begin{array}{c}\text { Hourly } \\
\text { Wages }\end{array}$ \\
\hline
\end{tabular}

Specification (a): Total Leave

\begin{tabular}{|c|c|c|c|}
\hline Females & $\begin{array}{c}.0121 \\
(.0166)\end{array}$ & $\begin{array}{c}.0508 \\
(.0248)\end{array}$ & $\begin{array}{c}.0269 \\
(.0293)\end{array}$ \\
\hline Males & $\begin{array}{c}.0088 \\
(.0128)\end{array}$ & $\begin{array}{c}.0409 \\
(.0252)\end{array}$ & $\begin{array}{c}.0254 \\
(.0273)\end{array}$ \\
\hline
\end{tabular}

Specification (b): Paid Leave

Females

.0994

.0870

$-.0595$

(.0371)

(.0307)

(.0617)

Males

1269

0659

$-.0427$

(.0264)

(.0316)

(.0564)

Sample Size

270

131

231

Notes: Table displays coefficients on parental leave regressors. Data are for 16 European countries over the 1969-1988 time period. All specifications include year and country effects. Total and paid leave refer to weeks of entitlement divided by 100 . Dependent variables are natural logs of labor market outcomes. Samples are limited to observations where information on all dependent variables are available. Observations are weighted to correct for heteroscedasticity. Standard errors are in parentheses. 


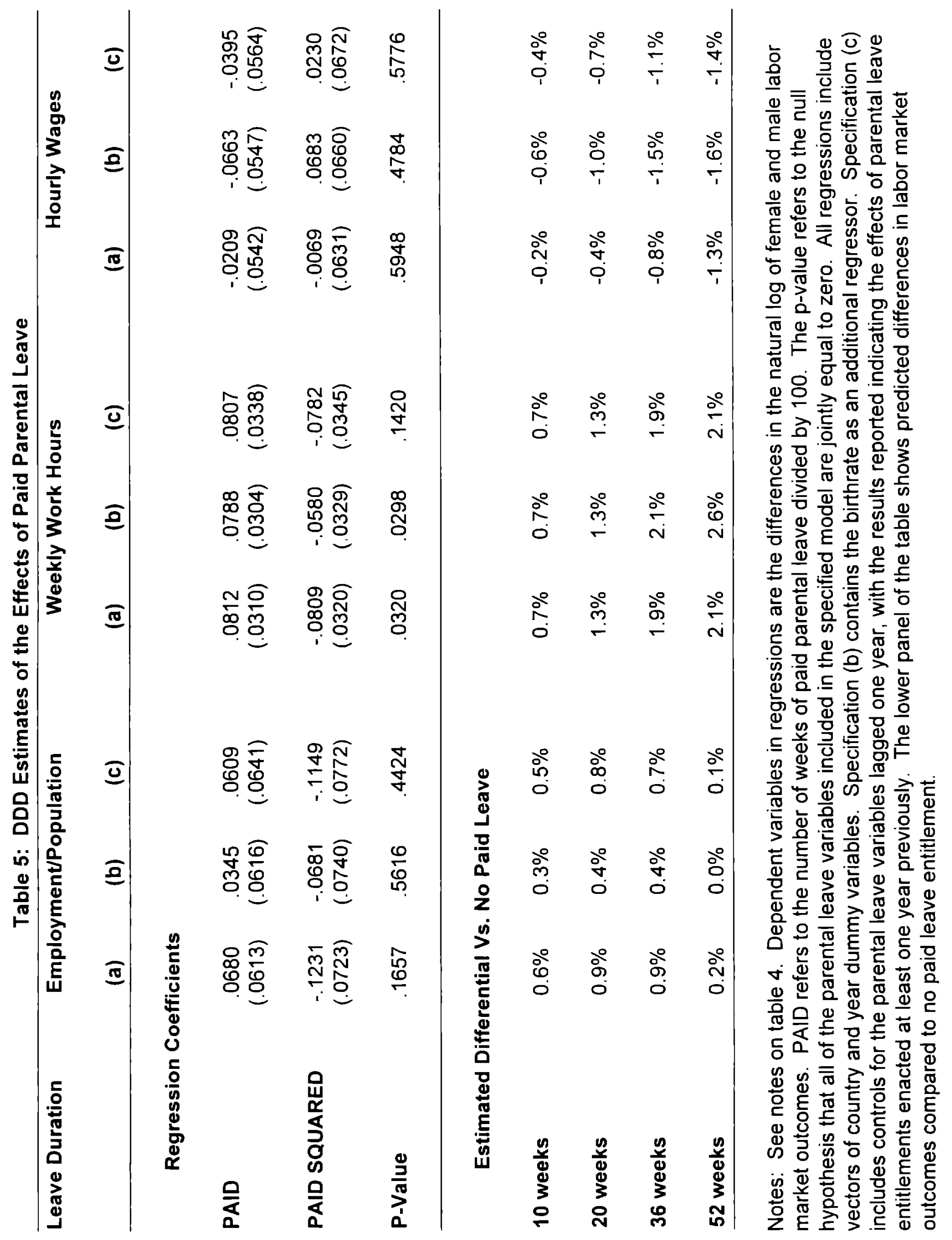


Table 6: DDD Estimates For Specifications With Country-Specific Time-trends

\begin{tabular}{ccc}
\hline Employment & Weekly Work \\
Population & Hours & Hourly Wages
\end{tabular}

Leave Duration
(a)
(b)
(a)
(b)
(a)
(b)

\section{Regression Estimates}

\begin{tabular}{|c|c|c|c|c|c|c|}
\hline ANYPAID & & $\begin{array}{c}.0247 \\
(.0121)\end{array}$ & & $\begin{array}{c}.0282 \\
(.0100)\end{array}$ & & $\begin{array}{c}.0169 \\
(.0151)\end{array}$ \\
\hline PAID & $\begin{array}{c}.2382 \\
(.0493)\end{array}$ & $\begin{array}{c}.1040 \\
(.0820)\end{array}$ & $\begin{array}{c}.0072 \\
(.0386)\end{array}$ & $\begin{array}{c}-.1856 \\
(.0781)\end{array}$ & $\begin{array}{c}-.0737 \\
(.0573)\end{array}$ & $\begin{array}{c}-.1772 \\
(.1089)\end{array}$ \\
\hline PAIDSQ & $\begin{array}{c}-.2598 \\
(.0587)\end{array}$ & $\begin{array}{c}-.1332 \\
(.0851)\end{array}$ & $\begin{array}{l}-.0320 \\
(.0490)\end{array}$ & $\begin{array}{c}.1415 \\
(.0778)\end{array}$ & $\begin{array}{c}.1346 \\
(.0680)\end{array}$ & $\begin{array}{c}-.2241 \\
(.1050)\end{array}$ \\
\hline P-Value & .0000 & .0000 & .6619 & .0375 & .1320 & .1517 \\
\hline \multicolumn{7}{|c|}{ Estimated Differential Vs. No Paid Leave } \\
\hline 10 weeks & $2.1 \%$ & $3.4 \%$ & $0.0 \%$ & $1.1 \%$ & $-0.6 \%$ & $0.1 \%$ \\
\hline 20 weeks & $3.8 \%$ & $4.1 \%$ & $0.0 \%$ & $-0.3 \%$ & $-0.9 \%$ & $-1.0 \%$ \\
\hline 36 weeks & $5.3 \%$ & $4.6 \%$ & $-0.2 \%$ & $-2.0 \%$ & $-0.9 \%$ & $-1.8 \%$ \\
\hline 52 weeks & $5.5 \%$ & $4.4 \%$ & $-0.5 \%$ & $-3.0 \%$ & $-0.2 \%$ & $-1.5 \%$ \\
\hline
\end{tabular}

Notes: See notes on tables 4 and 5. All specifications include vectors of year and country dummy variables as well as country-specific time-trends. ANYPAID is a dummy variable taking the value of one (zero) for positive (zero) weeks of paid leave entitlement. 





Table 8: DDD Estimates of Parental Leave Effects on the EP Ratios of Women of Childbearing Age
Regressor
(a)
(b)
(c)
(d)
(e)

\section{Regression Estimates}

ANYPAID

PAID

PAID SQUARED

Leave: 1 - 13 weeks

Leave: 14 - 26 weeks

Leave: $>26$ weeks

$\begin{array}{cc}.0682 & .0860 \\ (.0297) & (.0215)\end{array}$

1370

(.1863)

$(.1385)$

$-.0470$

$$
\text { (.1934) }
$$$$
\begin{array}{ll}
-.3145 \\
(.1575) & (.1934)
\end{array}
$$

$\begin{array}{ll}1447 & .1112\end{array}$

(.0252) (.0297)

$.0589 \quad .0739$

(.0216) (.0234)

$.1055 \quad .0893$

(.0272) (.0259)

\begin{tabular}{llllll} 
P-Value & .0032 & .0008 & .0001 & .0000 & .0008 \\
\hline
\end{tabular}

\section{Estimated Differential Vs. No Paid Leave}

10 weeks

20 weeks

36 weeks

52 weeks

\section{$4.1 \% \quad 8.5 \%$}

$7.6 \% \quad 9.8 \%$

$12.1 \% \quad 11.8 \%$

$14.9 \% \quad 13.5 \%$

Note: See notes on tables 4 through 6 . The dependent variable is the difference in the natural $\log$ of EP ratios between 25-34 and 45-54 year old women. All regressions include vectors of country and time dummy variables as well as country-specific time-trends. The categorical leave durations in specification (d) refer to paid entitlements while those in column (e) are for total (paid and unpaid) parental leave. The sample contains 160 observations. 
Fig 1: Consequences of A Mandated Benefit

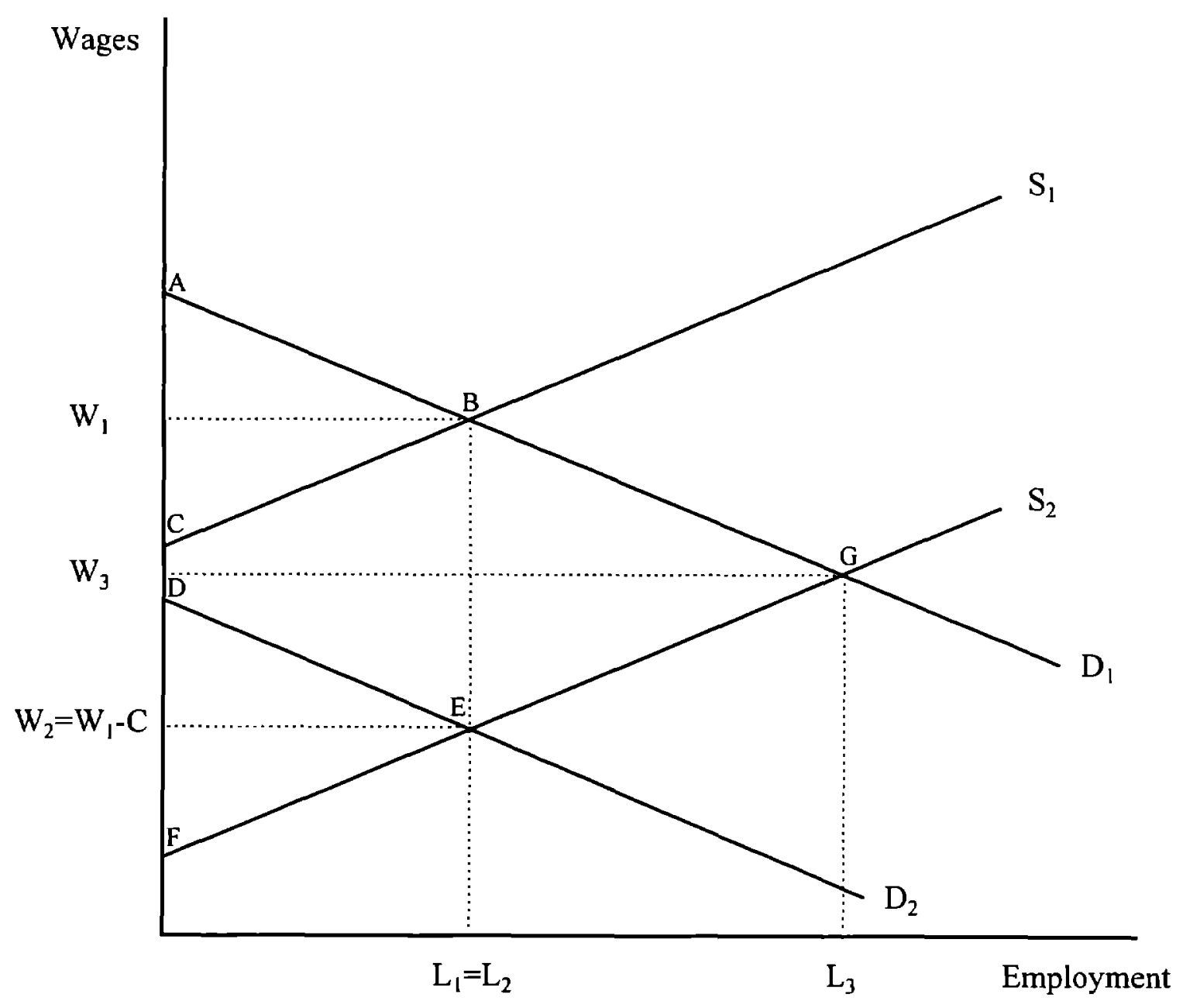


Fig 2a: Average Weeks of Parental Leave



Fig 2b: Average Employment/Population Ratios

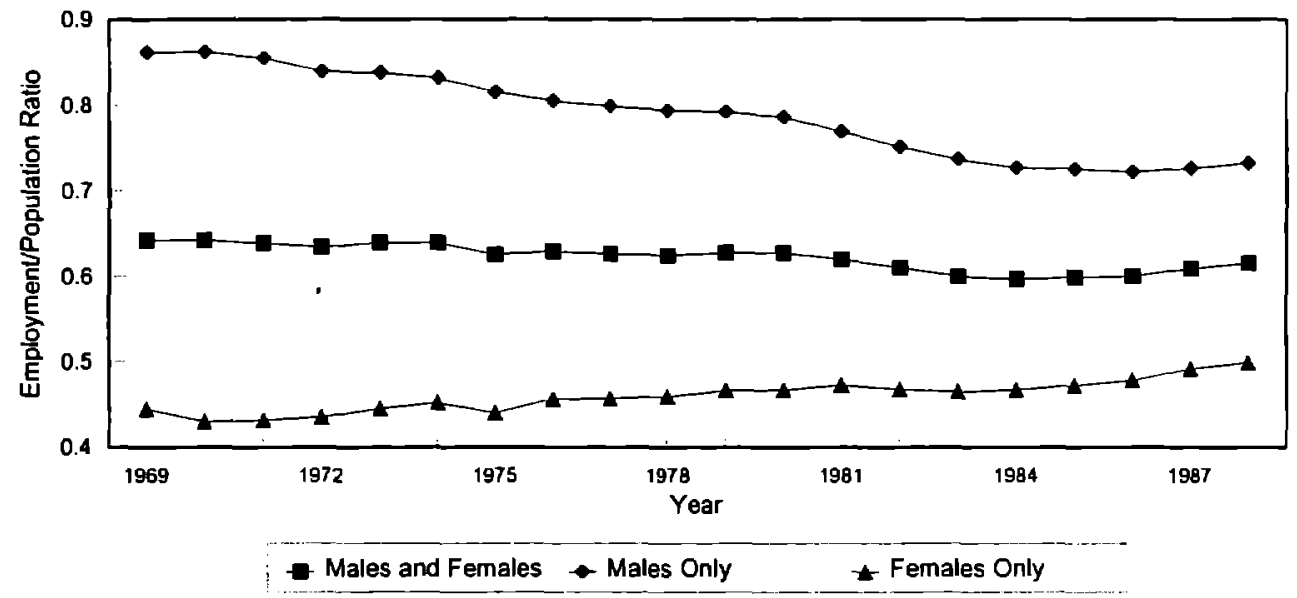

Fig 2c: Natural Log of Hourly Wages

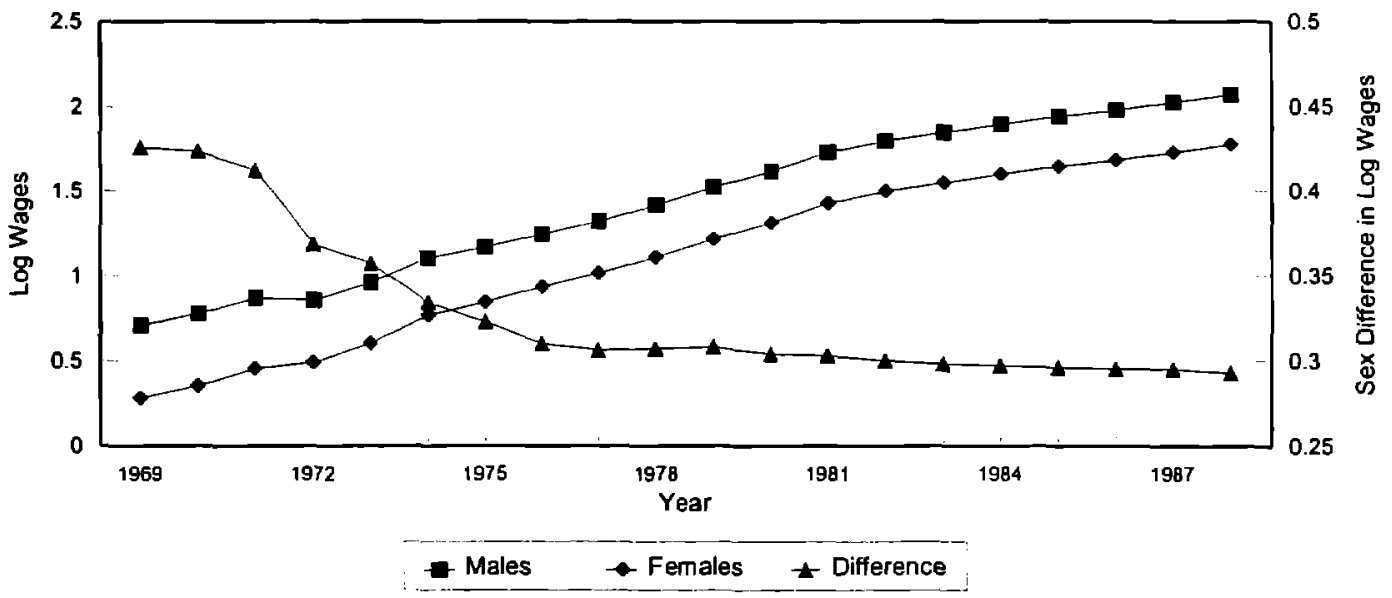


Fig. 3: Labor Market Outcomes as a Function of Paid Leave

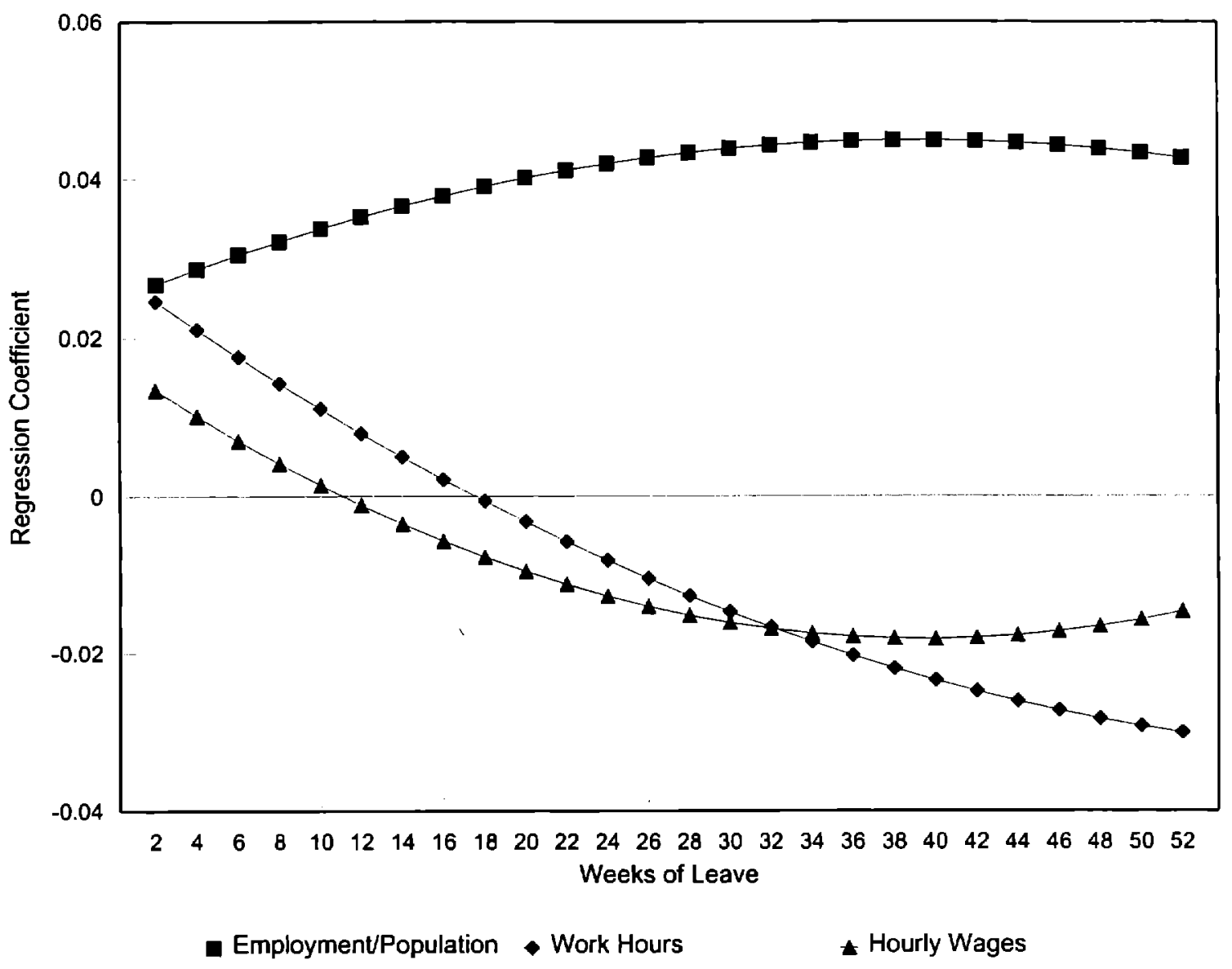

